\title{
Are the Typologies Determined by the Post-Critical Belief Scale Predicted Well by the Religious Attitudes and Behaviour of Maltese Undergraduate Students?
}

\author{
Mary Anne Lauri ${ }^{1}$, Josef Lauri ${ }^{2}$, Joseph Borg ${ }^{3}$ \\ ${ }^{1}$ Department of Psychology, University of Malta, Msida, Malta; \\ ${ }^{2}$ Department of Mathematics, University of Malta, Msida, Malta; \\ ${ }^{3}$ Department of Pastoral Theology and Canon Law, University of Malta, Msida, Malta. \\ Email: mary-anne.lauri@um.edu.m \\ Received May $15^{\text {th }}$, 2011; revised June 29 ${ }^{\text {th }}$, 2011; accepted July 29 $9^{\text {th }}, 2011$.
}

\begin{abstract}
Religious beliefs play an important role in the study of religious practices and behaviour. Wulff (1997) suggested that there are four basic attitudes towards religion: Literal Affirmation, Literal Disaffirmation, Reductive Interpretation and Restorative Interpretation. Building on this work, Duriez, Soenans and Hutsebaut (2005) constructed the Post-Critical Belief Scale (PCBS). In their work, Duriez at al. conducted a Principal Component Analysis of the responses to this questionnaire. It yielded two factors which partitioned 2-dimensional space into four quadrants corresponding to the four types of beliefs postulated by Wulff (1997). The research question which is addressed in this paper is whether there is an association between scores on the PCBS and religious practices and behaviour in a staunchly Catholic country like Malta where over $98 \%$ are baptized in the Roman Catholic Church. This question was addressed by administering a questionnaire to a random sample of 650 students at the University of Malta, of which 421 completed the questionnaire. Of those who answered the questionnaire, 349 were undergraduates. The questionnaire consisted of a number of questions about religious attitudes and behaviour, and also included the PCBS. The analysis of the association between membership of one of the four belief typologies and the participants' responses to other questions related to religious beliefs, religious practice and sexual norms was carried out using Discriminant Analysis. The results indicate that, at least in this sample of Maltese university students, these three measures do a reasonably good job in identifying membership in three of Wulff's four belief typologies.
\end{abstract}

Keywords: Face Recognition, Deception

\section{Introduction}

One of the most studied question in the psychology of religion is persons' perceptions of religion and religious beliefs (for example Bateson, 1993; Argyle, 2000; Fontaine et al., 2003). This paper focuses on the influential work carried out by Wulff (1997). Wulff postulated that attitudes towards religion can be classified along two dimensions, the Inclusion vs. Exclusion of Transcendence dimension and the Literal vs. Symbolic Dimension. He suggested that attitudes towards religion can be understood by taking into consideration these two important dimensions. The first dimension describes whether people accept the existence of God or some other transcendental being or whether they live by other guiding principles such as, for example, science. This dimension captures the extent of the religiosity or spirituality of the person. The second dimension describes how consistently the expressions of religious faith such as beliefs, images and rituals, are understood in a literal or symbolic way. According to Wulff, these two dimensions, Inclusion vs. Exclusion of Transcendence and the Literal vs. Symbolic dimension, describe the experience of religion and religious beliefs in a person's life. A person could fall in one of the four quadrants created by these two dimensions, Literal affirmation, Literal Disaffirmation, Reductive Interpretation and Restorative Interpretations. In a later study, Duriez et al. 2007, describe these same four quadrants using terminology as shown in brackets in Figure 1.

According to Wulff, people who fall into the quadrant called "Literal Affirmation" (or as described by Duriez et al. Literal Inclusion) can be described as intellectually immature and

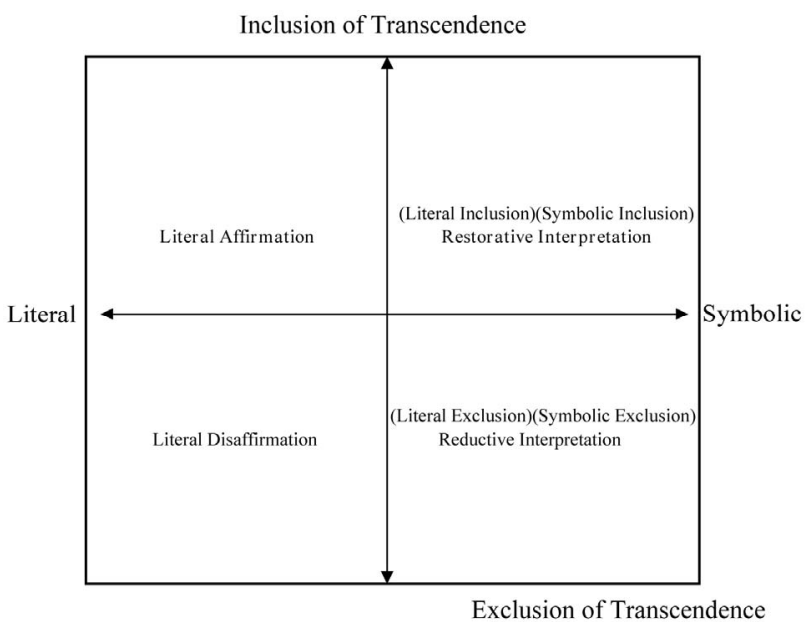

Figure 1.

Wulff's two dimensions describing attitudes towards religion. 
showing signs of "naïve credulity". Some of the people in this group may embrace religious fundamentalism but those who are nearer the centre may not be particularly conservative. Like people falling in the previously mentioned quadrant, people in the quadrant "Literal Disaffirmation" (or Literal Exclusion) also interpret religious language in a literal way. However these persons reject what is written or said in the Bible and other religious texts. These people tend to be more intellectual and this group would embrace those who lose sight of the possibility that religious words and ideas may refer to truths which must be understood metaphorically. The group of people who fall within the quadrant "Reductive Interpretation" (or Symbolic Exclusion) also denies the existence of the transcendental however they go beyond this denial and claim a privileged perspective on the meaning of religion's myths and rituals. Finally, the quadrant which Wulff termed "Restorative Interpretation" (or Symbolic Inclusion) is made up of people who believe in the existence of a transcendental realm but, unlike people in the Literal Inclusion quadrant who take religious language for granted, they search for the symbolic meaning of religious objects and ideas. They are usually complex, socially sensitive, insightful and relatively unprejudiced "post-critical” people, in the sense that they try "to encompass and transcend the criticism of religion formulated by people like Freud and Marx in order to find a symbolic meaning in religious language which has personal meaning" and thereby try "to go beyond the criticism on religion”. For a more detailed discussion of the four approaches the reader is referred to Wulff (1997).

\section{The Post-Critical Belief Scale}

Building on the work of Wulff, Hutsebaut (1996) constructed a 33-item scale called the Post-Critical Belief Scale (PCBS) which was designed to access a person's approach to Christian religion. Principal component analysis of the PCBS yielded a two dimensional solution dividing the two dimensional space into four quadrants which corresponded very well with Wulff's classification. The PCBS was subjected to tests to assess its construct validity. Duriez, Fontaine and Hutsebaut (2000) found that the subscales provide accurate measures of Wulff's four approaches to religion while Fontaine, Duriez, Luyten and Hutsebaut (2003) have shown that when individual differences in acquiescence are corrected for, two components that can be interpreted in terms of Inclusion vs. Exclusion of Transcendence and Literal vs. Symbolic are sufficient to explain the relation between the PCBS items. Duriez, Soenens and Hutsebaut (2005) proposed a shortened version of the scale with 18 short items. This version correlates strongly with the version proposed by Fontaine et al. (2003), with the correlation coefficients between scores on the long and the short scales greater than 0.90 (Duriez, Soenens, \& Hutsebaut, 2005).

In this shortened scale put forward by Duriez et al, each of the 18 items is a simple statement and the respondents are asked to indicate whether they agree or not with each statement on a Likert Scale. The items try to measure the four typologies of Wulff: Literal Inclusion (for example, the statement, "Only a priest can answer important religious questions”); Literal Exclusion (for example, "In the end, faith is nothing more than a safety net for human fears”); Symbolic Exclusion (for example, "There is no absolute meaning in life, only giving directions, which are different for every one of us”); and Symbolic Inclu- sion (for example, “The Bible holds a deeper truth which can only be revealed by personal reflection").

The works Duriez et al., 2000a and 2000b, especially the former, provided the idea for this study. In these works the researchers studied the relation between religion and racism. They were dissatisfied with measures such frequency of church attendance as indicators of religiosity, especially when investigating the relation between religiosity and other variables. They therefore turned to the PCBS. They concluded that while previous measures of religiosity were not sophisticated enough to account for attitudes towards complex topics such as racism, xenophobia and prejudice, scores on the PCBS were a better attempt at reconciling a person's religiosity and the person's attitudes towards such topics.

In this study we attempt to find out whether the shortened PBCS is valid in a culture which is different from that in which previous work using it has been carried out.

The PCBS is already an established scale, validated in some populations, and it relates to a theoretical construct of Wulff. The main motivation of our work rests on these facts and on the research of Duriez et al. (2000a, 2000b) where it has already been successfully used to compare religious beliefs with some attitudes such as racism and prejudice.

In our work, the shortened PCBS together with 34 other questions related to religious behaviour and attitudes was administered to a random sample of students of the University of Malta. One aim was to investigate how effective this scale is in bringing out Wulff's typology in a staunchly Catholic country like Malta where over $98 \%$ of the population are baptized in the Roman Catholic Church (World Factbook, 2008) although only $51 \%$ attend Church services regularly (Discern, 2006). It is found that even in this sample, Principal Component Analysis brings out Wulff's four categories. Subsequently we proceed to investigate how membership of one of Wulff's categories of religious belief is related to three areas of religious attitudes and behaviour: 1) dogma and faith, 2) religious behaviour and 3) sexual norms and practices. Discriminant Analysis is used in order to study these possible associations.

\section{Methodology}

\section{Sample}

The population of students at the University of Malta is just over 10,000 . To collect the data, a questionnaire was sent to a random sample of 650 students made available by the University Registrar. These students came from all the Faculties, Institutes and Centres of the University. The response rate was $65 \%(n=421)$. Both undergraduate and postgraduate students were included but since the number of postgraduate respondents was small and since these respondents were older, they were not included in this study. Moreover respondents who failed to answer more than three of the PCBS questions were excluded. This way, we worked with a sample of 350 respondents of which 137 were male (39\%) and 213 were female respondents (61\%). The mean age of the participants was 20.5 years; in fact, 332 students (95\%) were between 17 and 23 years of age. The majority of students (91\%) were Catholic, while the other $9 \%$ said they were either Christian, or embraced other religions or had no religion. Most students $(n=332)$ were 
single and the majority $(n=325)$ still lived with their parents. It is the norm in Malta for unmarried students to live with their parents since the island is small and the single University on the island can be reached by students in a very short time.

\section{Questionnaire}

The questionnaire was made up of 35 questions. The first 7 questions asked for demographic data. Questions 8 to 34 investigated students' attitudes and behavior regarding prayer, dogma, participation in Church activities, and teachings of the Catholic Church on social issues such as divorce, contraception and premarital cohabitation. Question 35 was the shortened version of the Post-Critical Belief Scale made up of 18 items with responses measured on a 5-point Likert scale.

\section{Results}

The responses to the questions in the Post-Critical Belief Scale (Duriez, Soenens, \& Hutsebaut, 2005) were first analysed. As in previous research (e.g., Duriez et al., 2004), and as we did in Lauri et al. (2009), a level of acquiescence estimation was subtracted from the raw scores, after which a Principal Component Analysis (PCA) was performed. The scree test for this PCA clearly pointed to a two-component solution. The two components between them accounted for 39\% of the sample variance, comparing very well with studies such as Duriez et al. (2005).

The loadings of the 18 items on the two principal components showed that they could be interpreted as Exclusion versus Inclusion of Transcendence and Literal versus Symbolic Interpretation, as in previous studies using this scale. For example, the first component loaded most heavily and positively on these items:

- The Bible is a guide, full of signs in the search of God, and not a historical account;

- Despite the high number of injustices Christianity has caused people, the original message of Christ is still valuable for me;

and it loaded most negatively on these items:

- In the end, faith is nothing more than a safety net for human fears;

- Faith is more of a dream which turns out to be an illusion when one is confronted with the harshness of life;

The second component was most positively loaded on these statements:

- God grows together with the history of humanity and therefore is changeable;

- I am well aware that my beliefs are only one possibility among so many others;

and it loaded most negatively on:

- God has been defined for once and for all and therefore is immutable;

- Only the major religions guarantee admittance to God.

We call these two extracted components INCLUSION and SYMBOLIC, respectively. A high score on the component INCLUSION indicates a tendency to include transcendence and spirituality in one's life. A high score on the component SYMBOLIC indicates a tendency to deal with religion in a symbolic way. Figure 2 shows the distribution of the respondents along these two dimensions and how they fall within the four typologies postulated by Wulff.

Each of the respondents was classified within one of the four typologies as follows. Those respondents who had a positive score on both INCLUSION and SYMBOLIC (HI/HS = High Inclusion/High Symbolic) were placed in the "Restorative Interpretation" category; respondents who had a negative score on INCLUSION and a positive score on SYMBOLIC (LI/HS = Low Inclusion/High Symbolic) were placed in the "Reductive

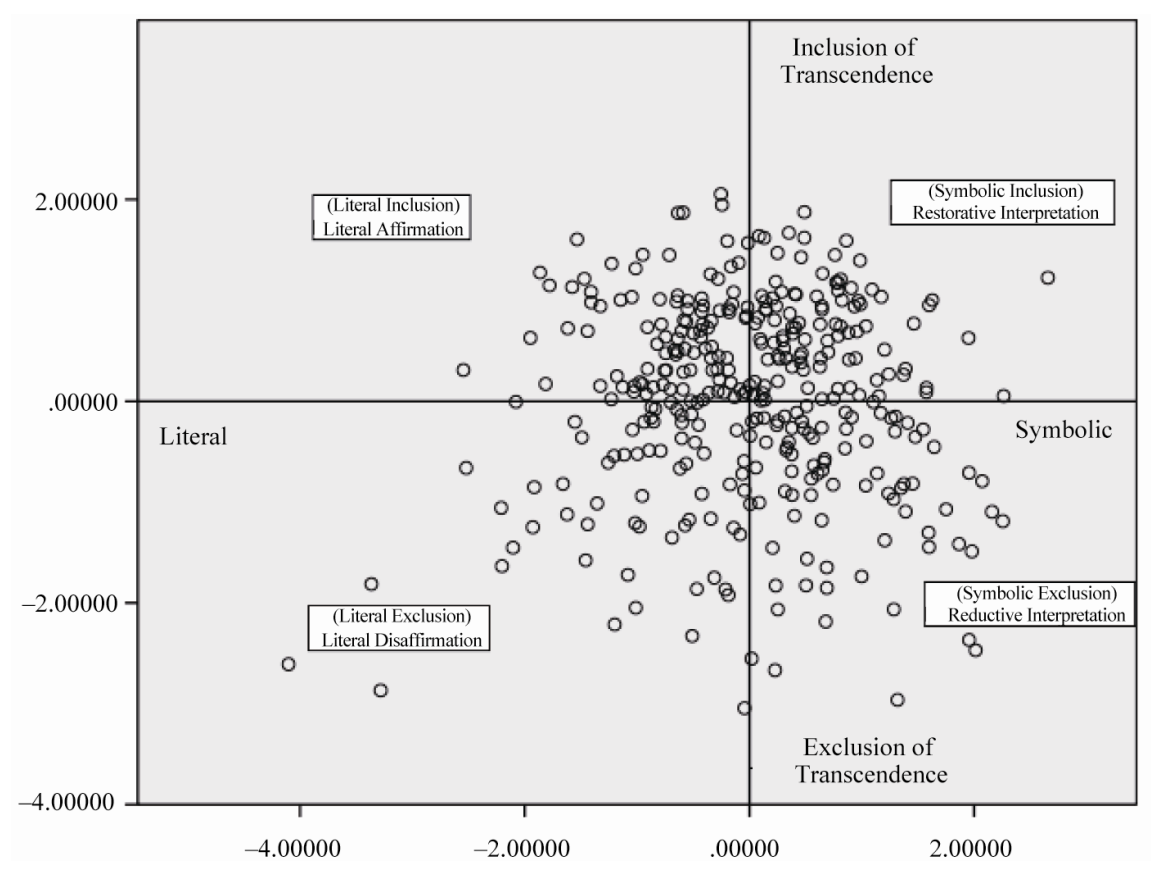

Figure 2.

Distribution of participants amongst the four typologies postulated by Wulff. 
Interpretation" category; those who had a positive score on INCLUSION but a negative score on SYMBOLIC (HI/LS) were placed in the Literal Affirmation category; and those respondents who had a negative score on both INCLUSION and SYMBOLIC (LI/LS) were placed in the Literal Disaffirmation category. These four categories (HI/HS; LI/HS; HI/LS and LI/LS) formed the levels of the variable QUADRANTS. Table 1 below gives some demographic statistics of the four groups determined by this first phase of the study.

Another aim of this study is to investigate whether respondents' scores on INCLUSION and on SYMBOLIC and their membership of Wulff's four typologies of religious beliefs are associated with their views on a number of religious doctrines and their behaviour in matters involving religion or morality.

\section{Relationship with Faith and Dogma, Religious Practice and Sexual Mores}

Besides questions asking for demographic data, the questionnaire contained 15 items related to religious beliefs and respondents were asked to mark those they believed in. The items were: God, The Holy Trinity, Jesus the Son of God, The Holy Spirit, Bodily Resurrection, Afterlife, Heaven and Hell, the Devil, Angels, God the Creator of all that exists, The Son of God made human (the Incarnation), Mary Mother of God, The virginity of Mary Mother of God, The Church, The Intercession of Saints, The Sacraments.

All these items referred to the Christian faith because the prevailing religion of the Maltese population is by far the Roman Catholic religion (Discern, 2006). For each of these items, belief was coded as 1 and disbelief was coded as 2 . A mean of the total score on these 15 items was then calculated for each respondent and stored in the variable FAITH. Since each item was scored as 1 for belief and 2 for disbelief, a lower value for FAITH denotes a higher overall belief in these items recorded by the respondent.

The next variable we computed was related to respondents' sexual behaviour and views. Here too they were given a number of questions to which they were to answer either yes (coded as 1 ) or no (coded as 2). The questions were:

- Do you approve of premarital sexual intercourse?

- Do you approve of premarital cohabitation?

- Do you agree that divorce should be legalised in Malta?

- During the last year, did you practise sexual intercourse?

Then the variable SEXUAL_PRACTICE was defined, for each respondent, as the average of the scores on these four questions. Again, the lower the score on SEXUAL_PRACTICE the more the respondent's views agreed with the Catholic Church's teaching.

The next variable which we computed was participation in religious practices. This was computed using the respondents' answer to these questions:

- How often do you go to Mass?

- How often do you receive Holy Communion?

- How often do you go to Confession?

All the responses were coded from 1 (most frequent) to 4 (never). The mean of the scores obtained was then calculated for each respondent. In order to standardise these values in relation with the variables FAITH, and SEXUAL_PRACTICE, the average obtained was scaled according to the equation

$$
[\text { RELIGIOUS_PRACTICE }=(\text { Average }+2) / 3] \text {. }
$$

As for the two variables FAITH and SEXUAL_PRACTICE, the lower the value of RELIGIOUS_PRACTICE the more in consonance was the respondent's score with the teachings of the Church.

In this second part of the study, discriminant analysis was used to study how the three numerical variables are related the categorical variable with four levels, a variable which we refer to as QUADRANTS.

\section{Discriminant Analysis}

The aim of this part of the study was to see how well the variables FAITH, RELIGIOUS_PRACTICE and SEXUAL_ PRACTICE could predict membership in the four Wulff typologies defined by the variable QUADRANTS. Using SPSS Version 18 we carried out discriminant analysis with these three variables as the explanatory variables and QUADRANT as the predicted variable. We carried out the analysis by using a random sample of $80 \%$ of the respondents to train the model and then testing the model on the remaining $20 \%$. The results are summarized in Table 2.

\section{The Training Sample}

The analysis yielded a model which classified correctly $65.7 \%$ of the respondents in the Reductive Interpretation (LI/HS) category, 63.2\% of those in the Literal Affirmation (HI/LS) category, and $49.3 \%$ of those in the Restorative Interpretation (HI/HS) category. However, only $8.2 \%$ of those in the Literal Disaffirmation (LI/LS) category were classified correctly; $41 \%$ of these respondents were classified in the Reductive Interpretation (LI/HS) category, and around 25\% were classified in each of the Literal Affirmation (HI/LS) category

Table 1.

Some demographic statistics of the respondents in the four typologies.

\begin{tabular}{lllll}
\hline & $\begin{array}{l}\text { Literal Inclusion } \\
\text { (Literal Affirmation) }\end{array}$ & $\begin{array}{l}\text { Literal Exclusion } \\
\text { (Literal Affirmation) }\end{array}$ & $\begin{array}{l}\text { Symbolic Exclusion } \\
\text { (Reductive Interpretation) }\end{array}$ & $\begin{array}{l}\text { Symbolic Inclusion } \\
\text { (Restorative Interpretation) }\end{array}$ \\
\hline Number of participants & 102 & 65 & 83 & 100 \\
Percentage of sample & $29.1 \%$ & $18.6 \%$ & $23.7 \%$ & $28.6 \%$ \\
Roman Catholic & 101 & 59 & 62 & 96 \\
Christian & 1 & 1 & 2 & 3 \\
No religion & 0 & 3 & 14 & 0 \\
Male & 41 & 24 & 33 & 39 \\
Female & 61 & 41 & 50 & 61 \\
Age range & $18-49$ & $18-26$ & $17-38$ & $17-44$ \\
Average age in years & 20.4 & 20 & 20.6 & 20.8 \\
\hline
\end{tabular}


Table 2.

Correct classification into the four quadrants.

\begin{tabular}{|c|c|c|}
\hline & $\begin{array}{l}\text { Percentage of cases correctly } \\
\text { classified }\end{array}$ & Remarks \\
\hline Cases included in model (80\%) & & A total of $49.8 \%$ of these cases were correctly classified \\
\hline Reductive Interpretation (LI/HS) & $65.7 \%$ & \\
\hline Restorative Interpretation (HI/HS) & $49.3 \%$ & \\
\hline Literal Disaffirmation(LI/LS) & $8.2 \%$ & $\begin{array}{l}41 \% \text { of respondents in this category were misclassified in the } \\
\text { Reductive Interpretation (LI/HS) category, and around } 25 \% \text { were } \\
\text { misclassified in each of the Literal Affirmation (HI/LS) category } \\
\text { and Literal Affirmations (HI/LS). }\end{array}$ \\
\hline Cases not included in the model (20\%) & & A total of $43.1 \%$ of these cases were correctly classified \\
\hline Reductive Interpretation (LI/HS) & $80.0 \%$ & \\
\hline Literal Affirmation (HI/LS) & $46.7 \%$ & \\
\hline Restorative Interpretation (HI/HS) & $50.0 \%$ & \\
\hline Literal Disaffirmation(LI/LS) & None & $\begin{array}{l}\text { Of respondents in this category, } 46 \% \text { were misclassified as } \\
\text { belonging to each of the LI/HS and HI/LS categories. }\end{array}$ \\
\hline
\end{tabular}

and Literal Affirmations (HI/LS). In all, the model correctly identified $49.8 \%$ of the selected cases.

\section{The Test Sample}

The figures for the $20 \%$ respondents who were not included in building the model were very similar (see Table 2, below) except that now, none of the respondents in the Literal Disaffirmation (LI/LS) category were classified correctly_of these $46 \%$ were misclassified as belonging to each of the $\mathrm{LI} / \mathrm{HS}$ and HI/LS categories. A total of $43.1 \%$ of the respondents in the training sample were correctly classified.

\section{Discussion}

It therefore seems that the three variables FAITH, RELIGIOUS_PRACTICE and SEXUAL_PRACTICE do a good job of categorising the LI/HS, HI/LS and HI/HS Wulff quadrants, certainly better than the prior probabilities from the sample percentages as shown in Table 1 . However, it is a very poor predictor of the Literal Disaffirmation (LI/LS) category. The question which arises is therefore why the respondents in the Literal Disaffirmation group are not classified correctly by a model based on faith, religious practice and sexual mores as explanatory variables?

In our view there could be at least three possible reasons, for the failure of the model to predict those falling in the quadrant Literal Dissaffirmation. One reason could be that the PCBS is a measure of attitudes, and since one's attitudes towards religion is a cognitive and affective measure, it is not necessarily predicted by or predicts one's behaviour. This debate about whether attitudes predict behaviour is a long-standing debate in social psychology and dates back to LaPierre's study in 1934 . This classical study was succeeded by thousands of other studies on this relationship between attitudes and behaviour and there is still no good model which can describe this association.

A second possible explanation could be that undergraduate students are going through a developmental stage where values, beliefs and practices are transient and maybe imposed. Almost all Maltese university students still live with their parents and probably must abide by their rules even though they may not necessarily agree with them. The faith of their elders is perhaps based on a literal interpretation of the Scripture and the Church's teachings, and this would be the type of religious belief that the students are accustomed to even though they do not necessarily agree with it. It could be that these students, as they acquire more maturity, will come to reject this literal belief and possibly not faith itself. Therefore their transient membership of this quadrant makes it difficult to identify this cohort via their beliefs, religious practices and sexual mores.

However, the most plausible explanation, in our view, lies in the deep cultural dimension of Catholicism in Malta. For most of these last two thousand years, being Maltese has been intricately interwoven with being a Catholic. Catholicism is the symbol of national identity. The Church dominates even the physical environment and the Maltese skyline of the village cores is still dominated by the parish churches. Catholic dogma influences the life of the individual in a substantial way and underpins social cohesion. The institutional Church also dominates the symbolic environment and value system. What the Church says is morally good or wrong is considered a yardstick by which to measure behaviour. This can be evidenced by the referendum campaign carried out in May 2011 on divorce. Malta is one of the only two countries in the world where it is still not possible to divorce one's spouse. These beliefs and values are reinforced in Sunday homilies, the weekly, and in some cases, daily worship, as well as during the special parish and national religious festivities held throughout the year.

So, in spite of a measure of secularisation, Maltese culture and way of life are still so imbued with Catholic beliefs, values and practice that even a Maltese non-believer would probably be different form a non-believer born and bred in a totally secularised environment. The former, could still say that he or she believes in God as it would be difficult, culturally and personally, to proclaim otherwise. It could be however that the God they believe in is a God different in "substance". This lack of "substance" in the God they believe in could then be manifested in the denial of other Catholic dogmas and especially in his neglect of Catholic moral precepts such as those about sexual behavior. So their disbelief and literal interpretation of religious teaching is not shared homogenously enough for them to be good predictors of membership in this quadrant.

Also, one's agreement or disagreement with the 18 items in 
the PCBS is somewhat a private matter. On the other hand, the responses to the questions making up the three explanatory variables have a social element in them. For example, one cannot miss Sunday Mass in private without friends or relatives coming to know about it. And such actions carry the risk of being ostracized in Catholic Malta.

\section{Concluding Remark}

The PCBS has been found to be valid in samples from countries such as Belgium, a very different scenario from Malta which is a small staunchly Catholic island. Although we have found that a Principal Component Analysis of responses to the 18-item questionnaire did give a two-dimensional solution supporting previous studies carried out by Hutsenbaut, Duriez, and others, we cannot claim that membership in Wulff's typologies can be predicted by behaviours one would expect to be congruent with attitudes implied by the typologies. Clearly, more work needs to be done to assess the validity of PCBS in different cultures. We also believe that such studies should try to investigate possible associations between scores on the PCBS and responses to other questions related to religiosity, as we have tried to do in this paper. This would make PCBS a powerful tool in researching the psychology of religion.

\section{References}

Argyle, M. (2000). Psychology and religion: An introduction. New York, NY: Routledge.

Bateson, C. D., Schroenrade, P., \& Ventis, W. L. (1993). Religion and the individual: A social-psychological perspective. New York, NY: Oxford University Press.
Discern (2006). Sunday mass attendance, census 2005, preliminary report. Maltese Islands.

Duriez, B., \& Hautsebaut, D. (2000). The relation between religion and racism: the role of post-critical beliefs. Mental Health, Religion and culture, 3, 85-102. doi:10.1080/13674670050002135

Duriez, B., Fontaine, J. R. J., \& Hutsebaut, D. (2000). A further elaboration of the Post-Critical Believe Scale: Evidence for the existence of the four different approaches to religion in flanders-Belgium. Psychologica Belgica, 40, 1-30.

Duriez, B., Soenens, B., \& Beyers, W. (2004). Personality, identity styles, and religiosity: An integrative study among late adolescents in Flanders. Journal of Personality, 72, 877-910. doi:10.1111/j.0022-3506.2004.00284.x

Duriez, B., Soenens, B., \& Hutsebaut, D. (2005). Introducing the shortened Post-Critical Belief Scale. Personality and Individual Differences, 38, 851-857. doi:10.1016/j.paid.2004.06.009

Duriez, B., Dezutter, J. Neyrinck, B., \& Hutsebaut, D. (2007). An introduction to the Post-Critical Belief scale: Internal structures and External relationships. Psyke and Logos, 28, 767-793.

Fontaine, J., R., Duriez, B., Luyten, P., \& Hutsebaut, D. (2003). The internal structure of the Post-Critical Belief scale. Personality and Individual Differences, 35, 501-518. doi:10.1016/S0191-8869(02)00213-1

Hutsebaut, D. (1996). Post-Critical Belief a new approach to the religious attitude problem. Journal of Empirical Theology, 9, 48-66. doi:10.1163/157092596X00132

Lauri, M. A., Lauri, J. \& Duriez, B. (2009). Social representations of religion of Maltese university Students. In E. P. Lamont (Ed.), Social psychology: New research (pp. 235-256). Hauppauge, NY: Nova Science Publishers.

LaPierre, R. T. (1934). Atitudes and actions. Social Forces, 13, 230237. doi:10.2307/2570339

The World Factbook (2008). Europe: Malta, Religions. URL (last checked 30 August 2011)

www.cia.gov/library/publications/the-world-factbook/geos/mt.html

Wulff, D. M. (1997). Psychology of religion: Classic and contemporary (2nd ed.). New York, NY: John Wiley \& Sons. 